\title{
Effect of folic acid decorated magnetic fluorescent nanoparticles on the sedimentation of starch molecules
}

\author{
S. Palanikumar • L. Kannammal • B. Meenarathi • \\ R. Anbarasan
}

Received: 6 January 2014/Accepted: 4 April 2014/Published online: 30 April 2014

(c) The Author(s) 2014. This article is published with open access at Springerlink.com

\begin{abstract}
Ferrite-folic acid (FA) nanohybrids were synthesized and characterized by various analytical tools like Fourier transform infrared spectroscopy, UV-Visible spectroscopy, fluorescence spectroscopy, field emission scanning electron microscopy, X-ray diffraction analysis and vibrating sample measurement techniques. After the nanohybrid formation, both the crystallinity and the magnetization values of ferrite were disturbed due to the surface functionalization of ferrite by FA. The role of nanohybrid on the structure-property relationship of starch, particularly the sedimentation of starch under three different $\mathrm{pHs}$, was evaluated. Again the magnetization value of $\mathrm{Fe}_{3} \mathrm{O}_{4}-\mathrm{FA} /$ starch nanocomposite system was reduced due to the encapsulation effect. The sedimentation velocity of starch under the influence of nanohybrid was enhanced in the acidic medium.
\end{abstract}

Keywords Ferrite Functionalization - Characterization · Starch $\cdot$ Nanocomposite $\cdot$ Sedimentation velocity

\section{Introduction}

In recent years, nanohybrid with magnetic property and with more functional groups has created a great interest and tempted the scientists to do researches because of its biocompatibility and eco-friendly nature. Among the available nanohybrids, super paramagnetic ferrite with different functionalities plays a vital role in bio-medical engineering

S. Palanikumar · L. Kannammal · B. Meenarathi .

R. Anbarasan $(\square)$

Department of Polymer Technology,

Kamaraj College of Engineering and Technology,

Virudhunagar 626001 , Tamilnadu, India

e-mail: anbu_may3@yahoo.co.in as an MRI agent and drug delivery material [1,2]. Various methodologies have been adopted for the synthesis of magnetic ferrite and its hybrids [3-5]. He et al. reported amino and carboxyl functionalized, silica-coated ferrite super paramagnetic nanocrystals for biological application [6]. In 2009, carboxylic acid stabilized iron oxide nanoparticle for use in magnetic hyperthermia; this report is available in the literature [7]. Dentronized iron oxide nanoparticle for multimodal imaging was done by Lamanna and co-workers [8]. In 2011, a review article was published by Huang and et al. [9] on the biochemical and biomedical applications of multi-functionalized magnetic nanoparticles. Tumor-targeting iron oxide nanoparticles were synthesized with the aid of click chemistry [10]. Even though the multi-functionalized ferrite has various biomedical applications, its role in the food chemistry is not explored. Hence, the key idea of the present investigation is the utilization of multi-functionalized ferrite in the food material such as a protective and sedimentation material.

Starch is one of the bio-resources of food materials among the available life saving materials on the earth. Such a soft energy material can be extracted from its source by various techniques. In 2002, Sajeev and research team [11] extracted the cassava starch from its ore which includes the wastage of $5 \%$ starch caused by the action of micro-organism in an aqueous medium. The wastage of starch under the influences of microbes can be reduced or nullified by increasing the sedimentation rate. This is the novelty of the present investigation. The bio-macromolecular scientists have been making more efforts in order to avoid food crisis in the near future. The effort includes the isolation [12-14], purification $[15,16]$, modification, utilization and regeneration of starch [17-20]. The literature survey reported that there is no suitable methodology available to avoid the $5 \%$ wastage of starch during the isolation process. 
Folic acid (FA) is a water-soluble, naturally occurring vitamin. FA is very much essential for various human bodily functions like synthesis and repair of DNA [21]. Deficiency of FA leads to various health problems such as anemia [22], depression and brain defects [23]. It is also used in the anti-cancer treatment [24, 25]. FA contains amino, imino, hydroxyl, carboxyl, imide and tertiary amine as functional groups. The availability of such functional groups can offer intermolecular hydrogen bonding with the incoming foreign material. This key idea is applied in the present investigation, i.e., the $\mathrm{OH}$ group of starch can interact with the various functional groups of FA and can increase the mass through the hydrogen bonding. This is the reason behind the utilization of FA in the present research work. Apart from the availability of various functional groups, FA has wide application in the bio-medical field as an anti-cancer agent. The rarity of the present investigation is the isolation of starch from the reaction medium by using FA-functionalized $\mathrm{Fe}_{3} \mathrm{O}_{4}$. During the settling process both magnetic force and gravitational force operate here and rapidly increase the settling rate. In such a way the wastage of food material like starch is saved for the better future. At the end of the process it is not necessary to remove $\mathrm{Fe}_{3} \mathrm{O}_{4}$ and FA from the starch because they are bio-compatible and essential for human health.

By a thorough literature survey, we could not find any report based on the FA-functionalized ferrite as an accelerator for the sedimentation rate of starch under different pHs through the secondary forces of attraction. In the present system, we took this case as a challenge and successfully made it by using a novel technique.

\section{Materials and methods}

\section{Materials}

The raw materials required for the preparation of $\mathrm{Fe}_{3} \mathrm{O}_{4}$ and its hybrid are as follows: ferrous sulphate $\left(\mathrm{FeSO}_{4}\right)$, ferric chloride $\left(\mathrm{FeCl}_{3}\right)$ and sodium hydroxide $(\mathrm{NaOH})$ were purchased from $\mathrm{CDH}$, India. The double distilled (DD) water was used for the solution preparation work. The ferrite nanoparticle was functionalized in the presence of folic acid (FA, Ranbaxy, India). The sedimentation velocity of Starch (Himedia, India) was studied under three different pHs like 2.5, 7.1 and 12.0.

Methods

\section{Synthesis of ferrite and FA-functionalized ferrite}

In the first step pristine ferrite nanoparticles were synthesized by the co-precipitation method. The procedure is given below: $5 \mathrm{~g}$ ferrous sulphate in $50 \mathrm{~mL}$ water was taken in a $250 \mathrm{~mL}$ round bottomed (RB) flask. $10 \mathrm{~g}$ ferric chloride in $50 \mathrm{~mL}$ water was added slowly into the RB. The slow addition was continued for $30 \mathrm{~min}$ at $45^{\circ} \mathrm{C}$ under nitrogen atmosphere under mild stirring condition [26]. After the complete mixing, the temperature of the reaction was reduced to room temperature with the simultaneous addition of $1 \mathrm{M} \mathrm{NaOH}$ solution under vigorous stirring. While adding sodium hydroxide the nucleation process started and there is a formation of ferrite nanocrystals. The ferrite formation can be confirmed by the appearance of the black coloration while adding $\mathrm{NaOH}$ solution. Now the $\mathrm{pH}$ was adjusted to 12.5 . After $2 \mathrm{~h}$ of nucleation reaction the contents were allowed to be stirred for another $1 \mathrm{~h}$. At the end of the reaction the contents were transferred to a $500 \mathrm{~mL}$ beaker and the same was kept on a magnetic bar. After certain period of time the black color precipitate settled down and the supernatant liquid was removed by pipetting without disturbing the medium. Thus obtained black colored precipitate was washed with $100 \mathrm{~mL}$ dd water for three times. This process was repeated in order to remove the impurities and the unreacted raw materials from the reaction medium. After the complete removal of water, the ferrite nanoparticles were dried at $110^{\circ} \mathrm{C}$ for $8 \mathrm{~h}$. Thus obtained fine black powder of ferrite was weighed and stored in a zipper lock bag. The reaction is explained in Scheme 1.

FA-functionalized ferrite was synthesized as follows: $5 \mathrm{~g}$ ferrous sulphate and $10 \mathrm{~g}$ ferric chloride in $100 \mathrm{~mL}$ water were mixed thoroughly; $2 \mathrm{~g}$ FA in $25 \mathrm{~mL}$ water was added slowly. The slow addition was continued for $30 \mathrm{~min}$ at $45{ }^{\circ} \mathrm{C}$ under nitrogen atmosphere under mild stirring condition; $5 \mathrm{~g} \mathrm{NaOH}$ in $25 \mathrm{~mL}$ water was added to the content slowly. The appearance of dark black color $(\mathrm{pH}$ $>10$ ) confirmed the formation of FA-functionalized ferrite. The stirring was continued for another $1 \mathrm{~h}$. Then the beaker was kept on a magnetic bar to isolate the FA-functionalized ferrite and to purify the nanohybrid material (Scheme 1). The purification process was continued three times with $50 \mathrm{~mL}$ fresh water. After the purification process the contents were filtered and dried at $110{ }^{\circ} \mathrm{C}$ for $8 \mathrm{~h}$. The dried sample was weighed and stored in a zipper lock cover.

\section{Synthesis of $\mathrm{Fe}_{3} \mathrm{O}_{4}-\mathrm{FA} /$ starch nanocomposite}

Then $2 \mathrm{~g}$ potato starch was dissolved in $100 \mathrm{~mL}$ water. The above-synthesized FA-decorated ferrite hybrid was added slowly under vigorous stirring condition. The FA-functionalized ferrite can be loaded at different percentage weights. After the reaction, the contents were evaporated to dryness. The final product, starch/ $\mathrm{Fe}_{3} \mathrm{O}_{4}-\mathrm{FA}$ systems were dried, weighed and stored in a zipper lock cover. Please refer Scheme 1. 


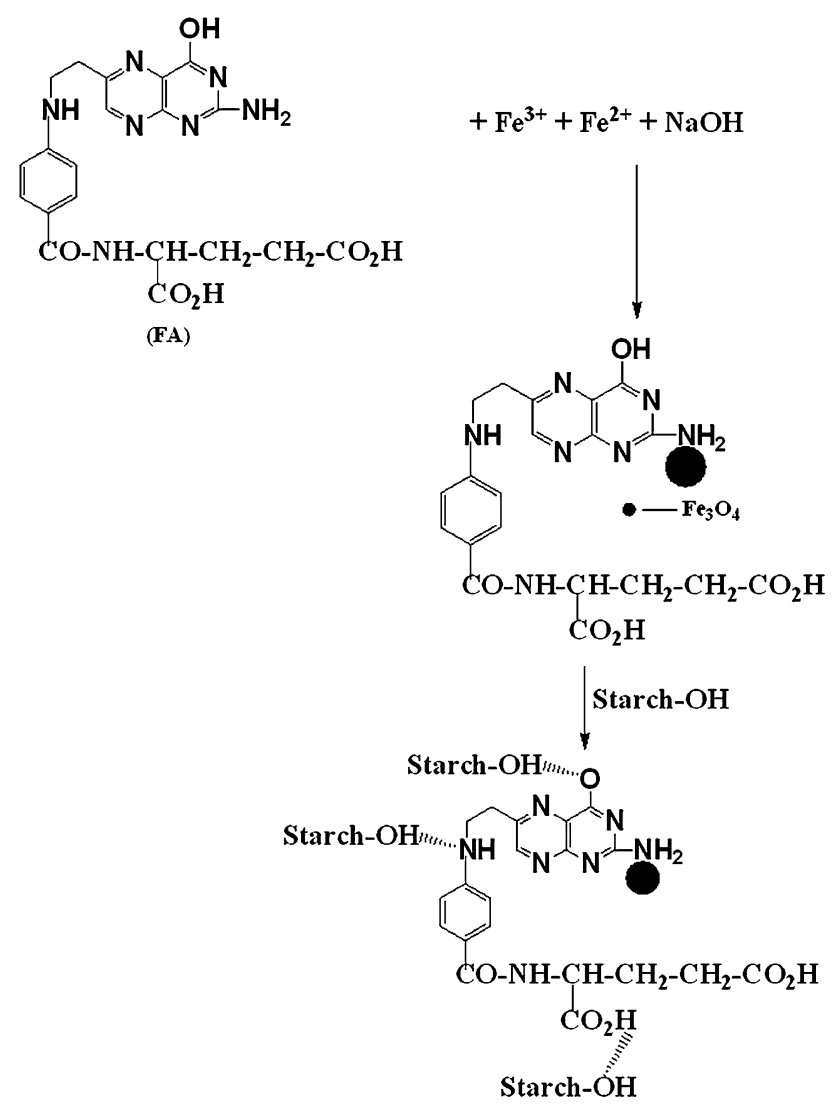

Scheme 1 Synthesis of starch encapsulated FA decorated ferrite

\section{Analytical characterizations}

Magnetic measurements were carried out with a superconducting quantum interference device magnetometer (Lakesore-7410-VSM, USA) with magnetic fields up to $7 \mathrm{~T}$ at $32{ }^{\circ} \mathrm{C}$. Jasco V-570 instrument was used for UV-Visible spectrum measurements. Then $2 \mathrm{mg}$ of sample was dissolved in $10 \mathrm{~mL}$ water under ultrasonic irradiation for $10 \mathrm{~min}$ and subjected to UV-Visible spectral measurements. Fourier transform infrared (FTIR) spectrum was taken, by using Shimadzu $8400 \mathrm{~S}$, Japan model instrument, from 4,000 to $400 \mathrm{~cm}^{-1}$ by $\mathrm{KBr}$ pelletization method. Photoluminescence spectrum was measured with the help of PL, Jasco Model FP-6000, Japan, instrument, from 300 to $700 \mathrm{~nm}$. X-ray diffraction (XRD, XS08, Bruker, USA) was recorded with an advanced instrument and scanning from the $2 \theta$ value of $10^{\circ}-80^{\circ}$ at a scanning rate of $2^{\circ} \mathrm{min}^{-1}$. The surface morphology of the samples was scanned by a scanning electron microscope (SEM, JSM 6300, JEOL model).

\section{Settling velocity}

The settling velocity of starch in the presence of FAfunctionalized ferrite nanoparticle under three different $\mathrm{pHs}$, was determined by using the following formula [11]: $v_{0}=\frac{g d_{\mathrm{s}}^{2}\left(\rho_{\mathrm{s}}-\rho_{\mathrm{w}}\right)}{18 \mu_{\mathrm{w}}}$

where, $v_{0}$ is the free falling velocity in $\mathrm{ms}^{-1}, g$ is the acceleration due to gravity in $\mathrm{m} \mathrm{s}^{-2}, d_{\mathrm{s}}$ is the diameter of starch particle, $\rho_{\mathrm{s}}$ is the density of starch particle in $\mathrm{kg} \mathrm{m}^{-3}, \rho_{\mathrm{w}}$ is the density of water in $\mathrm{kg} \mathrm{m}^{-3}, \mu_{\mathrm{w}}$ is the viscosity of water in $\mathrm{kg} \mathrm{m}^{-1} \mathrm{~s}^{-1}$. The \% weight of hybrid was varied between 0.01 and $0.05 \%$. When compared with the amount of starch, it is negligible. Hence it is not necessary to remove the hybrid after the settling of starch.

\section{Result and discussions}

For the sake of convenience, the results and the discussion part is subdivided into two parts, namely (1) characterization of surface functionalized ferrite and (2) characterization and sedimentation behavior of $s t a r c h / \mathrm{Fe}_{3} \mathrm{O}_{4}-\mathrm{FA}$ nanocomposite system.

\section{Characterization of surface functionalized ferrite}

Figure 1a indicates the FTIR spectrum of pristine ferrite. The metal oxide stretching appeared at $606 \mathrm{~cm}^{-1}$. The $\mathrm{OH}$ stretching of water intercalated ferrite can be seen at $3,457 \mathrm{~cm}^{-1}$. The FTIR spectrum of ferrite was clearly explained by Baharvand [26]. Ferrite after the surface functionalization with FA is given in Fig. 1b. The important peaks are characterized below. The $-\mathrm{NH}$ stretching appeared at $3,279 \mathrm{~cm}^{-1}$. The aliphatic $\mathrm{C}-\mathrm{H}$ stretching appeared at $2,888 \mathrm{~cm}^{-1}$. A peak at $1,651 \mathrm{~cm}^{-1}$ is depicted to amide linkage of FA. The aromatic $-\mathrm{CH}$ stretching appeared around $1,000 \mathrm{~cm}^{-1}$. The $\mathrm{C}-\mathrm{H}$ out-of-plane bending vibration appeared at $800 \mathrm{~cm}^{-1}$. The coexistence of two iron atoms on the same plane can be observed at $3,487 \mathrm{~cm}^{-1}$. Appearance of these new peaks apart from $\mathrm{M}-\mathrm{O}$ stretching confirmed the functionalization of ferrite by FA.

The UV-Visible spectrum of ferrite before and after surface functionalization reaction is shown in Fig. 1c, d, respectively. A broad peak at $334 \mathrm{~nm} \mathrm{[27]} \mathrm{confirmed} \mathrm{the}$ presence of iron (Fig. 1c). The ferrite after the surface functionalization exhibited a broad peak at $371 \mathrm{~nm}$ is corresponding to the iron atom. A shoulder at $261 \mathrm{~nm}$ is ascribed to the $\pi \rightarrow \pi^{*}$ transition of FA (Fig. 1d). The red shift in the absorbance peak at $371 \mathrm{~nm}$ confirmed the surface functionalization of ferrite by FA. The UV-Visible spectrum of ferrite and stimuli-responsive magnetic nanoparticle are reported in the literature [28]. Our results coincide with their report.

Fluorescence spectrum of pristine ferrite (Fig. 1e) and FA surface functionalized ferrite (Fig. 1f) confirmed the 

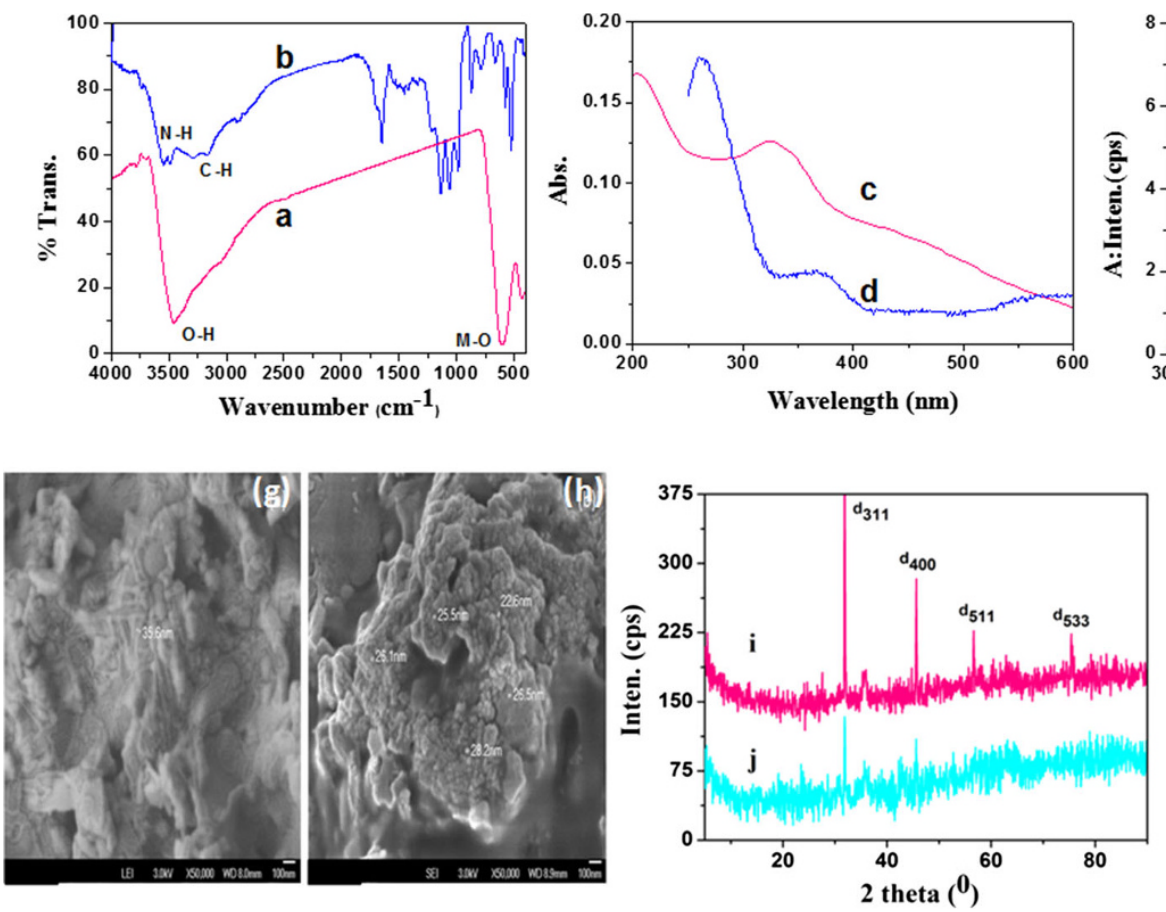

Fig. 1 FTIR spectrum of $(a)$ ferrite, $(b)$ ferrite-FA hybrid; UVVisible spectrum of $(c)$ ferrite, $(d)$ ferrite-FA hybrid; fluorescence spectrum of $(e)$ ferrite, $(f)$ ferrite-FA hybrid; FESEM of $(g)$ ferrite,

bio-medical application of ferrite particularly in the bioimaging field. Before and after the surface functionalization reaction, ferrite exhibits an emission peak at $351 \mathrm{~nm}$. Ferrite after the surface functionalization with FA produced higher peak intensity with blue shifting. The higher fluorescence emission intensity (FEI) of $\mathrm{Fe}_{3} \mathrm{O}_{4}-\mathrm{FA}$ hybrid system added more value towards the bio-imaging and targeted drug delivery field. The blue shift of the emission peak can be narrated by the reduction in the size of ferrite by the FA. Moreover, both ferrite and FA are biocompatible in nature and can be very much useful in the cancer cell identification with simultaneous treatment. The higher FEI of $\mathrm{Fe}_{3} \mathrm{O}_{4}$-FA hybrid system is due to the binding of ferrite with the amino group of FA. This extended the electronic transition between ferrite and amino group of FA. In 2011, Kady and co-workers [29] reported that iron oxide is a fluorescence quencher. But in the present investigation ferrite is acting as a fluoro probe in the presence of FA. The FEI value confirmed the bio-medical application of ferrite hybrid.

The particle size and morphology of ferrite before and after surface functionalization with FA is given in Fig. 1g, $\mathrm{h}$, respectively. Before the surface functionalization reaction, the ferrite shows different shapes like sphere and rod. The diameter and the length of the rod were determined as 35.6 and $210 \mathrm{~nm}$, respectively (Fig. 1g). The ferrite synthesized in the presence of FA exhibits the nanosphere with
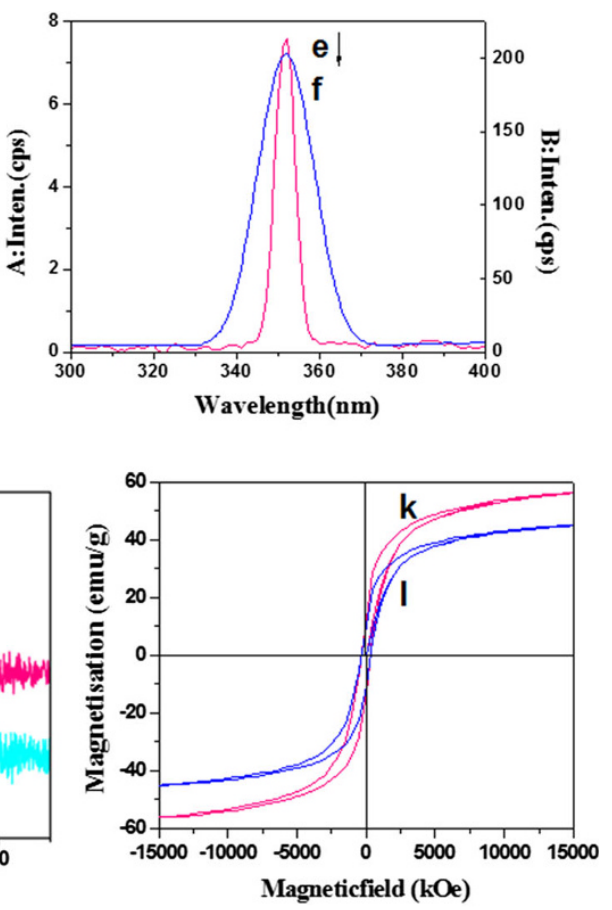

(h) ferrite-FA hybrid; XRD of $(i)$ ferrite, $(j)$ ferrite-FA hybrid; VSM of $(k)$ ferrite, $(l)$ ferrite-FA hybrid

the size of $\sim 25 \mathrm{~nm}$. It is very interesting to note that ferrite synthesized in the presence of FA exhibits a unique shape and size. It means that the added FA controlled both the size and shape of the ferrite. By way of surface functionalization reaction, one can attain the dual benefits such as sphere with the uniform size. From the literature, one can understand that the sphere form [6] of ferrite is more effective than the rod form in the drug delivery application. This is because of increase in surface area to volume ratio. Above all, the added FA is acting as a dispersing agent and hence the agglomeration of ferrite nanoparticle was restricted to some extent. Thus the surface functionalization process offers more advantages.

The surface functionalization of ferrite by FA can further be confirmed by XRD spectrum. Figure 1i represents the XRD of pristine ferrite. The diffractogram exhibits $d_{311}, d_{400}, d_{511}$ and $d_{533}$ crystal planes at $31.8^{\circ}, 45.5^{\circ}, 56.7^{\circ}$ and $75.7^{\circ}$, respectively. A sharp crystalline peak at $31.8^{\circ}$ is responsible for the increase in basal spacing (the distance between the two crystal planes) of ferrite. Figure $1 \mathrm{j}$ enumerates the XRD of ferrite after the surface functionalization with FA. Here also one can observe crystalline peaks corresponding to $d_{311}$ and $d_{400}$ crystal planes [29]. After the surface functionalization reaction there is no change in the peak position. At the same time the peak intensity was suppressed. If there is any change in peak position or disappearance of $d_{311}$ crystal plane, one can come to an idea 
about the intercalation or exfoliation reaction. In fact such a change in peak position was not observed. This confirmed the absence of intercalation or exfoliation reaction during the functionalization of ferrite by FA. The important point noted here is the peak intensity which was drastically reduced, resulted in the appearance of the peaks at $56.7^{\circ}$ and $75.7^{\circ}$ disappeared. By noting the decrease in the peak intensity of $d_{311}$ and $d_{400}$ one can easily predict the surface functionalization of ferrite by FA. In the case of FA one can see six different functionalities such as $-\mathrm{NH}_{2},-\mathrm{OH}$, $-\mathrm{NH}-,-\mathrm{CO}_{2}-\mathrm{H}, \mathrm{CO}-\mathrm{NH}, \mathrm{C}=\mathrm{N}$. Among those, the amino group has good metal surface binding activity. Moreover, the FTIR spectrum confirmed the presence of $-\mathrm{NH}$ stretching. This urged us to suggest the amino group of FA which might interact with the ferrite surface in an alkaline $\mathrm{pH}$. The present investigation on XRD of ferrite before and after functionalization with FA concludes the simple surface adsorptions of FA onto ferrite, i.e., surface functionalization of ferrite by FA.

The surface functionalization of ferrite by FA can be supported by vibrating sample measurement (VSM) data. The magnetic moment value of pure ferrite (Fig. 1k) was determined as $53.6 \mathrm{emu} \mathrm{g}^{-1}$. The FA-functionalized ferrite exhibits the VSM value of $43.5 \mathrm{emu} \mathrm{g}^{-1}$ (Fig. 11). The decrease in VSM value explores the surface binding of ferrite by FA. Chemically the decrease in VSM value of FA-functionalized ferrite can be explained as follows: The carboxyl group of FA may degrade the crystal structure of ferrite to some extent due to strong acidic nature. The degradation in crystal structure of ferrite can be determined by XRD. Hence due to the partial degradation of ferrite and surface binding of ferrite with FA the VSM value was reduced. FA has two carboxyl groups and under the influence of alkaline $\mathrm{pH}$ it was readily ionized to give $\mathrm{CO}_{2}{ }^{-}$and $\mathrm{Na}^{+}$. The negatively charged carboxyl group may interact with the central metal ion. This may also disturb the super paramagnetism of ferrite. In general, the surface binding decreases the VSM value of the ferrite [26].

Characterization and sedimentation behavior of starch/ $\mathrm{Fe}_{3} \mathrm{O}_{4}-\mathrm{FA}$ nanocomposite system

The effect of FA-decorated ferrite nanoparticles on the structure of starch under three different $\mathrm{pHs}$ was studied. The FTIR spectrum of $s t a r c h / \mathrm{Fe}_{3} \mathrm{O}_{4}$-FA nanocomposite synthesized under acidic medium is given in Fig. 2a. A broad band at $3,416 \mathrm{~cm}^{-1}$ is due to the $\mathrm{OH}$ stretching of starch [26]. The $\mathrm{C}-\mathrm{H}$ stretching of starch is observed at $2,893 \mathrm{~cm}^{-1}$. The $\mathrm{CH}$ bending vibration of starch is noted at $1,596 \mathrm{~cm}^{-1}$. The aliphatic ether linkage and the $\mathrm{CH}$ out-ofplane bending vibrations appeared at 1,018 and $845 \mathrm{~cm}^{-1}$, respectively. As usual the metal oxide stretching of ferrite

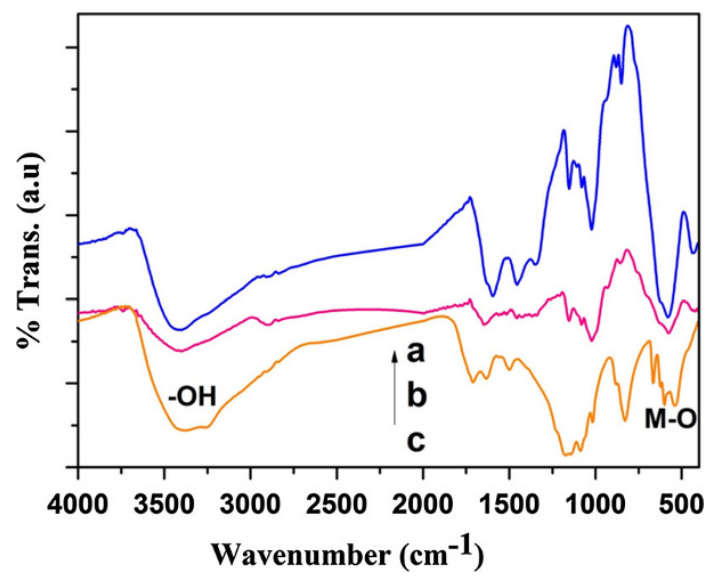

Fig. 2 FTIR spectrum of starch treated under (a) acidic $\mathrm{pH}$, (b) alkaline $\mathrm{pH},(c)$ neutral $\mathrm{pH}$

can be seen at $577 \mathrm{~cm}^{-1}$. The shifting in the peak position of ferrite confirmed the encapsulation effect of starch. The $\mathrm{M}-\mathrm{O}$ stretching of pristine ferrite, hybrid and nanocomposite with starch under acidic $\mathrm{pH}$ appeared at 606,527 and $577 \mathrm{~cm}^{-1}$, respectively. The encapsulation of hybrid by starch moieties can be explained in terms of hydrogen bonding. Unfortunately, the intermolecular hydrogen bonding between $\mathrm{OH}$ group of starch and amino/carboxyl group of FA did not appear here. This is due to the strong $-\mathrm{OH}$ stretching of starch.

The FTIR spectrum of starch/Fe $\mathrm{F}_{3} \mathrm{O}_{4}-\mathrm{FA}$ is shown in Fig. $2 \mathrm{~b}$ under the influence of alkaline $\mathrm{pH}$. The important band noted here is the appearance of $\mathrm{O}^{-} \mathrm{Na}^{+}$peak at $1,636 \mathrm{~cm}^{-1}$. This is due to the conversion of hydroxyl group of starch into $\mathrm{M}-\mathrm{O}$ group, i.e., formation of $\mathrm{O}^{-} \mathrm{Na}^{+}$. Under the alkaline $\mathrm{pH}$, the added $\mathrm{NaOH}$ not only nucleates the ferrite but also stabilizes the structure of starch by converting the $\mathrm{OH}$ group into $\mathrm{O}^{-} \mathrm{Na}^{+}$like structure. Figure $2 c$ represents the FTIR spectrum of $\operatorname{starch} / \mathrm{Fe}_{3} \mathrm{O}_{4}-\mathrm{FA}$ nanocomposite system synthesized under neutral $\mathrm{pH}$. Here also one can watch $-\mathrm{OH}, \mathrm{C}-\mathrm{H}$, ether $\mathrm{C}-\mathrm{O}-\mathrm{C}$ linkage. Apart from these bands some new bands also appeared due to the change in the structure of starch. At neutral $\mathrm{pH}$, the secondary alcoholic group of starch was oxidized to keto group. Indeed, one can pinpoint a band at $1,627 \mathrm{~cm}^{-1}$ due to the bending vibration of $-\mathrm{OH}$ group of starch. The $\mathrm{M}-\mathrm{O}$ stretching is strongly observed around $560 \mathrm{~cm}^{-1}$. By analyzing the FTIR results one can come to a conclusion that during alkaline treatment there will be a formation of $\mathrm{O}^{-} \mathrm{Na}^{+}$like structure and conversion of secondary alcoholic group into keto group at neutral $\mathrm{pH}$.

The thermal stability of starch treated under three different pHs was studied by DSC and TGA. Figure 3a denotes the DSC thermogram of starch treated under acidic $\mathrm{pH}$ in the presence of FA-decorated ferrite. The DSC thermogram exhibits one broad endothermic peak at 
Fig. 3 DSC of starch/ferriteFA nanocomposite system prepared under $(a)$ acidic $\mathrm{pH}$, (b) alkaline $\mathrm{pH},(c)$ neutral $\mathrm{pH}$, TGA of starch/ferrite-FA nanocomposite system prepared under $(d)$ acidic $\mathrm{pH},(e)$ alkaline $\mathrm{pH},(f)$ neutral $\mathrm{pH}$
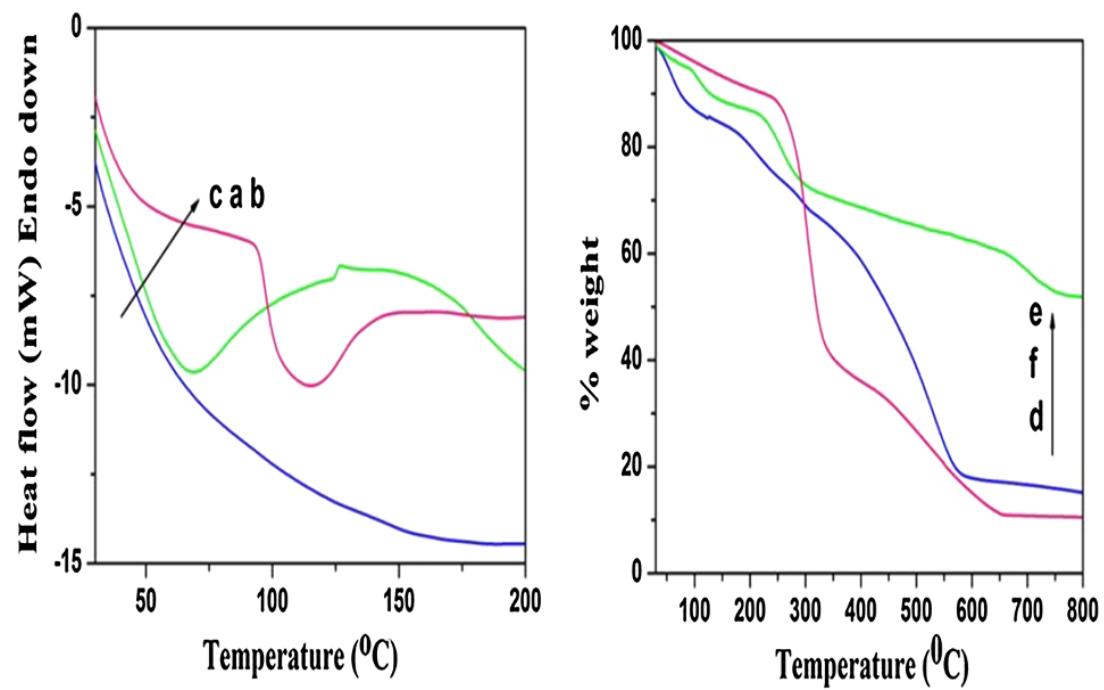

$67.4^{\circ} \mathrm{C}$ and it corresponds to the melting of starch crystals. Figure $3 \mathrm{~b}$ explains the DSC thermogram of starch treated under alkaline $\mathrm{pH}$. The thermogram exhibits a strong and broad endothermic peak at $111^{\circ} \mathrm{C}$. This higher melting temperature is associated with the $\mathrm{O}^{-} \mathrm{Na}^{+}$like ionic structure. The DSC thermogram of starch treated under neutral $\mathrm{pH}$ failed to produce a melting peak due to the gelatinization effect (Fig. 3c). Up to $200{ }^{\circ} \mathrm{C}$ no phase transition peak is noted. DSC of starch treated with different inorganic acids was studied by Sajeev and coworkers [30]. Our result coincides with their report.

The thermal degradation temperature of starch under three different $\mathrm{pHs}$ in the presence of FA-functionalized ferrite is shown in Fig. 3. Figure 3d exhibits a thermogram corresponding to the starch treated under acidic $\mathrm{pH}$. The thermogram exhibited a three-step degradation process. The first minor weight loss below $100{ }^{\circ} \mathrm{C}$ is accounted for by the removal of moisture and physisorbed water molecules. The second minor weight loss around $250{ }^{\circ} \mathrm{C}$ is demonstrated by the removal of chemisorbed water molecules and some amount of FA from the nanocomposite structure. The third major weight loss around $500{ }^{\circ} \mathrm{C}$ is responsible for the degradation of starch backbone. After the complete degradation, above $750{ }^{\circ} \mathrm{C}$, it shows that $16 \%$ weight residue remained. The percentage of weight residue that remained above $750{ }^{\circ} \mathrm{C}$ is directly proportional to the amount of ferrite present in the nanocomposite system. Figure $3 \mathrm{e}$ remembers the TGA thermogram of starch nanocomposite treated under alkaline $\mathrm{pH}$. Again the thermogram exhibits a four-step degradation process. The first and second minor weight loss up to $130{ }^{\circ} \mathrm{C}$ is covered by the removal of moisture and physisorbed water molecules. The third minor weight loss around $250{ }^{\circ} \mathrm{C}$ is due to the removal of chemisorbed water molecules. The fourth minor weight loss around $750{ }^{\circ} \mathrm{C}$ is due to the starch backbone degradation. Above $750{ }^{\circ} \mathrm{C}$ it shows $52 \%$ of the remaining weight residue. This confirmed the stable structure of $\mathrm{O}^{-} \mathrm{Na}^{+}$like ionic form of starch. Figure $3 \mathrm{f}$ shows the TGA thermogram of starch treated under neutral $\mathrm{pH}$ with the three-step degradation process. The first minor weight loss up to $230{ }^{\circ} \mathrm{C}$ is demonstrated by the removal of moisture and physisorbed water molecules. A major weight loss around $300{ }^{\circ} \mathrm{C}$ is due to the removal of chemisorbed water molecules and the free starch molecules degradation. The third major weight loss at $518{ }^{\circ} \mathrm{C}$ is explained by the degradation of starch backbone. Above $750{ }^{\circ} \mathrm{C}$ it gives $10 \%$ weight residue that remained. On close comparison, the alkaline-treated starch exhibited higher thermal stability due to the presence of ionic structure. The weight loss of around $250-300{ }^{\circ} \mathrm{C}$ is associated with the complex process including the dehydration of saccharide rings and depolymerization [18]. We agree with the results of Piyada et al. [18] under acidic and neutral $\mathrm{pH}$, but in the alkaline $\mathrm{pH}$, the structure of starch becomes different.

The surface morphology of starch treated under three different pHs is shown in Fig. 4. Under acidic pH (Fig. 4a) starch exhibited a rigid rod-like morphology with the size of $5.1 \mu \mathrm{m}$. Starch treated under alkaline $\mathrm{pH}$ (Fig. 4b) showed a fine granular morphology with the size of $0.50 \mu \mathrm{m}$. This is due to the nucleation effect of $\mathrm{NaOH}$. The surface morphology of starch treated under neutral pH (Fig. 4c) exhibits a broken stone-like morphology with the size of $0.60 \mu \mathrm{m}$. The above surface morphology study under different $\mathrm{pHs}$ of starch exhibits different shape and size.

The magnetic moment value of starch/ $\mathrm{Fe}_{3} \mathrm{O}_{4}-\mathrm{FA}$ system treated under three different $\mathrm{pHs}$ is mentioned in Fig. 5. Figure 5a-c reveals the VSM loop of starch treated under acidic, alkaline and neutral $\mathrm{pH}$, respectively. The VSM value of ferrite was determined from the loop as $27.8,40.4$ and $36.2 \mathrm{emu}^{-1}$ corresponding to the acidic, alkaline and 

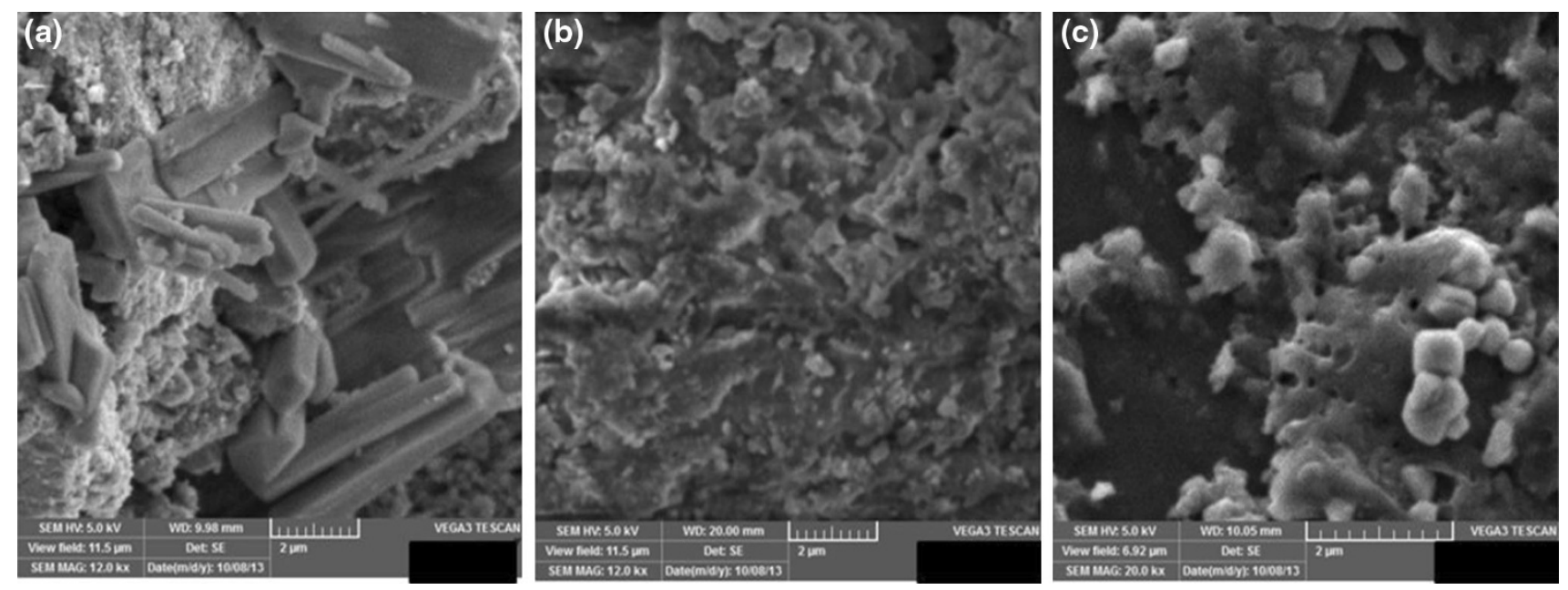

Fig. 4 SEM image of starch/ferrite-FA nanocomposite system prepared under a acidic $\mathrm{pH}, \mathbf{b}$ alkaline $\mathrm{pH}, \mathbf{c}$ neutral $\mathrm{pH}$

neutral $\mathrm{pH}$ treatment. On comparison it could be found that the alkaline-treated ferrite exhibited the highest value. This is due to the nucleation of ferrite under alkaline $\mathrm{pH}$. The acidic-treated ferrite shows the lowest VSM value due to the structural degradation of ferrite under the influence of negatively charged species. In overall comparison the VSM value of pristine ferrite is the highest one. The hybrid system exhibited the lower VSM value due to the surface functionalization reaction. After the encapsulation by starch, the acid-treated ferrite exhibited the lowest VSM value due the structural degradation of both starch and ferrite. Auoak and co-workers [31] studied the VSM of ferrite at different \% weight loadings of PEVA. It was found that the VSM value was reduced with the increase in $\%$ weight loading of PEVA due to the encapsulation effect. In the present investigation also we explain the concept through the encapsulation effect.

\section{Settling velocity}

The main aim of the present investigation is to study the settling velocity of starch at different $\mathrm{pHs}$ in the presence of FA-functionalized ferrite. While adding starch in the aqueous dispersion for FA-functionalized $\mathrm{Fe}_{3} \mathrm{O}_{4}$ the starch molecule was found to be settled and increase in particle size leads to fast settling of starch. Moreover, the inter and intra molecular hydrogen bonding (Scheme 1) also accelerated the settling velocity of starch. In addition, $\mathrm{Fe}_{3} \mathrm{O}_{4}$ was also added in order to increase the settling velocity through the magnetic force. In this juncture gravitational force through hydrogen bonding and increase in particle size as well as the magnetic force through the added $\mathrm{Fe}_{3} \mathrm{O}_{4}$ combinedly operated and increase the settling velocity of starch. Figure 6 indicates the starch sediment height with respect to different time interval at different $\%$ weight

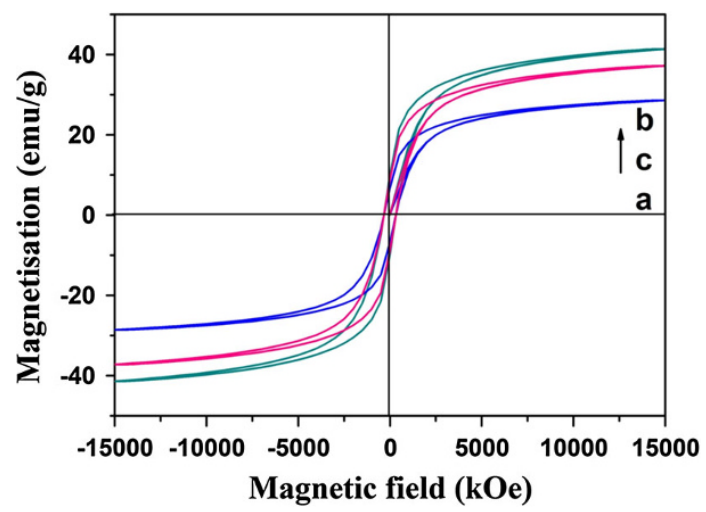

Fig. 5 VSM of starch/ferrite-FA nanocomposite system prepared under $(a)$ acidic $\mathrm{pH},(b)$ alkaline $\mathrm{pH},(c)$ neutral $\mathrm{pH}$

loading of hybrid under acidic $\mathrm{pH}$. It was noted that while increasing the percentage weight load of FA decorated ferrite, the settling velocity of starch is also activated. This is due to the presence of intermolecular hydrogen bonding between $\mathrm{OH}$ group of starch and amino or carboxyl group FA decorated starch. The settling velocity was determined as $0.6021 \times 10^{-6} \mathrm{~m} \mathrm{~s}^{-1}$. Figure 7 explains the role of $\mathrm{Fe}_{3} \mathrm{O}_{4}-\mathrm{FA}$ hybrid system on the sedimentation height of starch at different time interval under alkaline $\mathrm{pH}$. Again it was noted that while increasing both the time and the percentage weight loading of $\mathrm{Fe}_{3} \mathrm{O}_{4}-\mathrm{FA}$ system, the settling velocity was calculated as $5.9 \times 10^{-9} \mathrm{~m} \mathrm{~s}^{-1}$. This value is definitely lower than that of settling velocity of starch under acidic $\mathrm{pH}$. Under the influence of neutral $\mathrm{pH}$ (Fig. 8) the settling velocity was calculated as $7.7 \times 10^{-9} \mathrm{~m} \mathrm{~s}^{-1}$. In overall comparison the starch treated under acidic $\mathrm{pH}$ exhibited the highest settling velocity. This is due to the rigid structure of starch and bigger size starch. Due to the bulky size both the gravitational and magnetic forces are encouraged. Hence the acid-treated 


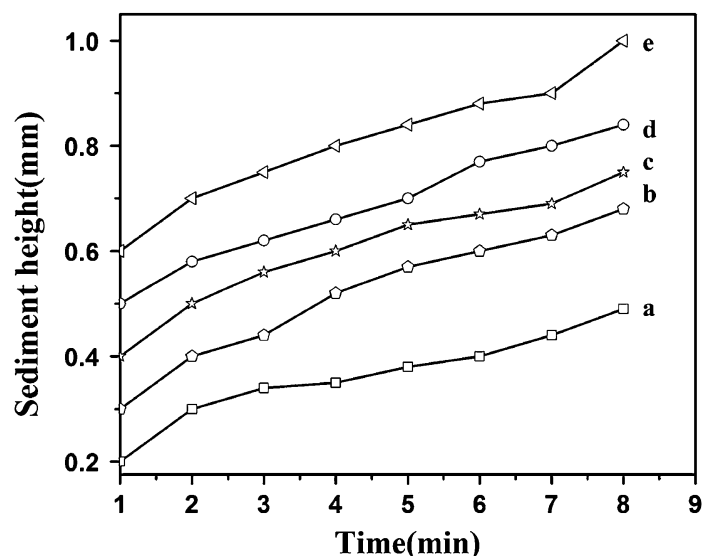

Fig. 6 Plot of time vs. sedimentation height of starch/ferrite-FA nanocomposite system prepared under $(a)$ acidic $\mathrm{pH}$ at different $\%$ weight loading of hybrid

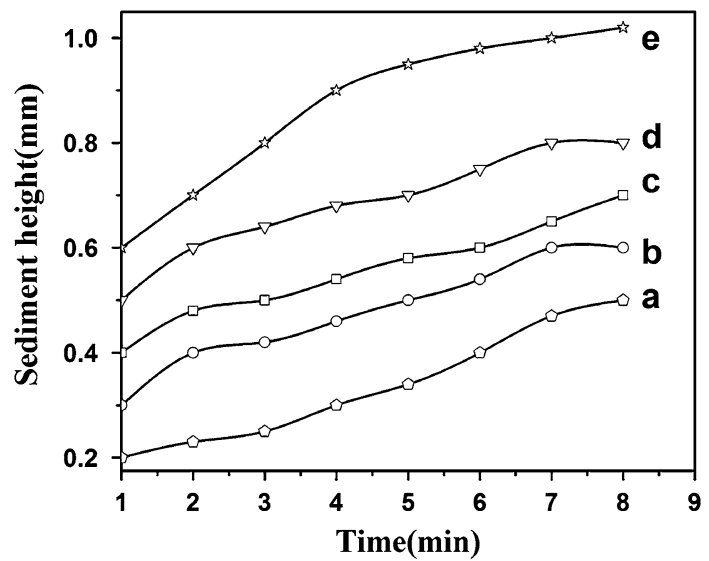

Fig. 7 Plot of time vs. sedimentation height of starch/ferrite-FA nanocomposite system prepared under $(b)$ alkaline $\mathrm{pH}$ at different $\%$ weight loading of hybrid

starch settled down very fast. The settling velocity of starch under different experimental conditions was done by Sajeev and co-workers $\left(1.69 \times 10^{-4} \mathrm{~m} \mathrm{~s}^{-1}\right.$ in an aqueous medium) [32] and another research team [27]. The present investigation yielded somewhat higher settling velocity due to the influence of ferrite-FA nanohybrid system with the magnetic force and additional gravitational forces. In such a way the wastage of starch can be avoided. This is the novelty of the present investigation.

We know that FA contains carboxyl, hydroxyl, amino group, imino group, amide and tertiary amines like functional groups. These functional groups can offer more and more hydrogen bonding with the hydroxyl group of starch as mentioned in Scheme 1. The increase in hydrogen bonding favors the mass gain and increases the settling velocity. When starch molecules were dispersed in an

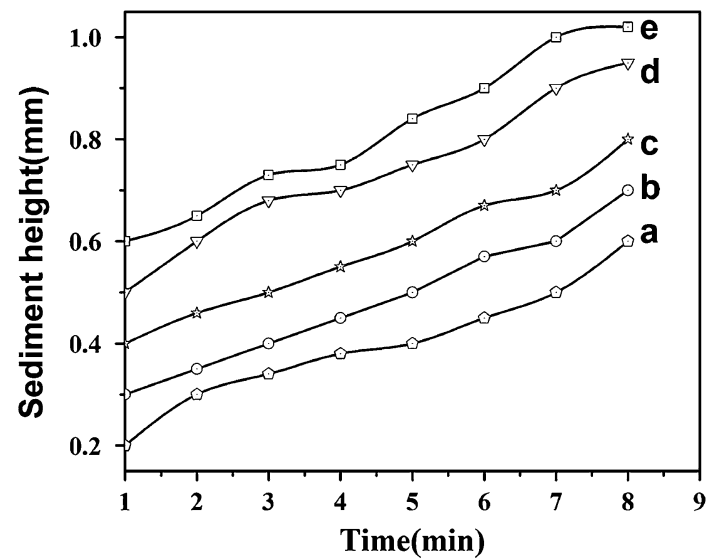

Fig. 8 Plot of time vs. sedimentation height of starch/ferrite-FA nanocomposite system prepared under $(c)$ neutral $\mathrm{pH}$ at different $\%$ weight loading of hybrid

aqueous medium in the size of the starch was increased the settling of starch. Above all, the FA-functionalized $\mathrm{Fe}_{3} \mathrm{O}_{4}$ also encouraged the settling velocity of starch under the influence of magnetic force. Due to the following three effects such as swelling, gravitational force and magnetic force the settling velocity of starch was increased in an aqueous medium. The sedimentation velocity of structurally modified starch [33] and polyaniline [34] under the influence of magnetic force was reported in the literature. The basic principle of the present investigation coincides with the literature $[33,34]$.

\section{Conclusions}

From the present investigation the important points are summarized here as conclusion. The FTIR spectrum confirmed the presence of $\mathrm{M}-\mathrm{O}\left(\sim 600 \mathrm{~cm}^{-1}\right)$. The red shifting in the absorbance spectrum of ferrite declared the surface functionalization of ferrite by FA. From the FESEM images one can come to a conclusion that both the size and shape were very much controlled by the added FA. Unfortunately, the crystallinity was reduced by the surface functionalization reaction. On thorough FTIR analysis of starch/ $\mathrm{Fe}_{3} \mathrm{O}_{4}-\mathrm{FA}$ exhibited a degraded structure under the acidic medium. Starch treated under acidic $\mathrm{pH}$ reveals bigger particle size of starch and hence the high settling velocity $\left(7.7 \times 10^{-9} \mathrm{~m} \mathrm{~s}^{-1}\right)$ of starch. The VSM value enumerated that the structure of $\mathrm{Fe}_{3} \mathrm{O}_{4}$ was degraded under acidic medium $\left(27.8 \mathrm{emu} \mathrm{g}^{-1}\right)$.

Acknowledgments Mrs. G. Vijayalakshmi, Assistant Professor from the Department of English is gratefully acknowledged for her valuable help during this manuscript preparation.

Open Access This article is distributed under the terms of the Creative Commons Attribution License which permits any use, 
distribution, and reproduction in any medium, provided the original author(s) and the source are credited.

\section{References}

1. Wei, H., Insin, N., Lee, J., Han, H.S., Cordero, J.M., Liu, W., Bawendi, M.G.: Compact zwitter ion coated iron oxide nanoparticles for biological applications. Nano Lett. 12, 22-25 (2012)

2. Wang, S.H., Shri, X., Antwerp, M.V., Cao, Z., Swanson, S.D., Bi, X., Barker Jr, J.R.: Dendrimer functionalized iron oxide nanoparticle for specific targeting and imaging of cancer cells. Adv. Funct. Mater. 17, 3043-3059 (2007)

3. Shu, Z., Wang, S.: Synthesis and characterization of magnetic nano sized $\mathrm{Fe}_{3} \mathrm{O}_{4} / \mathrm{MnO}_{2}$ composite particles. J. Nanomater. 340217, 1-5 (2009)

4. Franger, S., Berthet, P., Berthon, J.: Electrochemical synthesis of ferrite nanoparticle in alkaline aqueous solution containing complexing agents. J. Solid State Electrochem. 8, 218-223 (2011)

5. Peng, S., Sun, S.: Synthesis and characterization of monodispersed hollow ferrite nanoparticle. Angew. Chem. Int. Ed. 46, 4155-4158 (2007)

6. He, Y.P., Wang, S.Q., Li, C.R., Miao, Y.M., Wu, Z.Y., Zou, B.S.: Synthesis and characterization of functionalized silica coated ferrite superparamagentic nano crystals for biological applications. J. Phys. D Appl. Phys. 38, 1342-1350 (2005)

7. Thomas, L.A., Dekkar, L., Kallumadil, M., Southern, P., Nair, S.P., Pankhurst, Q.A., Parkin, I.P.: Carboxylic acid functionalized iron oxide nanoparticle for use in magnetic hyperthermia. J. Mater. Chem. 19, 6529-6535 (2009)

8. Lamanna, G., Stotz, M.K., Chaouachi, H.M., Ghobril, C., Billotey, B., Flesh, D.F.: Dendronized iron oxide nanoparticle for multi modal imaging. Biomaterials 32, 8562-8573 (2011)

9. Huang, S.H., Juang, R.S.: Bio-chemical and biomedical applications of multifunctionalized magnetic nanoparticles: a review. J. Nanopart. Res. 13, 4411-4430 (2011)

10. Huang, C., Neoh, K.G., Kang, E.T.: Combined ATRP and click chemistry for designing stable tumor targeting superparamagnetic iron oxide nanoparticle. Langmuir 28, 563-571 (2012)

11. Sajeev, M.S., Kaliappan, R., Narayanan, V.V.S., Thangavel, K.: Kinetics of gravity settling of cassava starch in its aqueous suspension. Biosys. Eng. 83C37, 327-337 (2002)

12. Prochaska, K., Kedziora, P., Thanh, J.L., Lewandowicz, G.: Surface activities of commercial food grade modified starches. Colloids Surf. B Bioinform. 60, 187-194 (2007)

13. Madariaga, B.C., Aquirre, J.: Combination treatment of corn starches waste water by sedimentation, microfiltration and reverse osmosis. Desalination 279, 255-290 (2011)

14. Stolt, M., Oinonen, S., Autio, K.: Effect of high pressure on the physical properties of barley starch. Innov. Food Sci. Eng. Tech. 1, 167-175 (2001)

15. Da, G., Ferret, F., Marechal, P.A., Thanh, M.L., Marouze, C., Dufour, D.: Modelling small scale cassava starch extraction. Simulation of the reduction of water consumption through a recycling process. Process Biochemi. 45, 1837-1842 (2010)

16. Renault, F., Chrini, N.M., Gimbert, F., Padot, P.M., Chrini, G.: Cationized starch based material as a new ion-exchange adsorbent for the removal of C.I. acid blue-25 from aqueous solution. Bio Res. Tech. 99, 7573-7586 (2008)

17. Closs, C.B., Petit, B.C., Roberts, I.D., Tolstoguzov, V.B., Escher, F.: Phase separation and rheology of aqueous starch/galactomannan systems. Carbohydr. Polym. 39, 67-77 (1999)

18. Piyada, K., Waranyou, S., Thawien, W.: Mechanical, thermal and structural properties of rice starch films reinforced with rice starch nano crystals. Int. Food Res. J. 20(1), 439-449 (2013)

19. Iizuka, K., Aishima, T.: Starch gelation process observed by FTIR/ATR spectrophotometry with multivariate data analysis. J. Food Sci. 64(4), 653-658 (1999)

20. Thygesan, L.G., Lokke, M.M., Micklander, E., Engelsen, S.B.: Vibrational microscopy of food. Raman versus FTIR. Trends Food Sci. Tech. 14, 50-57 (2003)

21. Bailey, S.W., Ayling, J.E.: The extremely slow and variable activity of dihydrofolate reductase in human liver and implications for high folic acid intake. Proc. Natl. Acad. Sci. USA. 106(36), 15424-15429 (2009)

22. Weinstain, S.J., Hartman, T.J., Stolzenberg-solomon, R.: Honul association between prostate cancer and serum folate, vitamin $\mathrm{B}(6)$, vitamin $\mathrm{B}(12)$ and homocrystals. Cancer Epidemiol. Biomark. Prev. 12, 1271-1272 (2003)

23. Wolff, J.E., Hauch, H., Kuhl, J., Egeler, R.M., Jurgens, H.: Dexamethasone increased hepatotoxicity and acute venal failure. Leuk. Lymphoma 29(1-2), 205-209 (1998)

24. Kim, Y.I.: Does the high folate intake increase the risk of breast cancer? Nurti. Rev 64, 468-475 (2006)

25. Johansson, M., Appleby, P.N., Allen, N.E.: Circulating concentrations of folate and vitamin B12 in relation to prostate cancer risk results from the European prospective investigation. Cancer Epidemiol. Biomark. Prev. 17(2), 279-285 (2008)

26. Baharvand, H.: Encapsulation of ferromagnetic iron oxide particle by polyester resin. E Polym. 102, 1-9 (2008)

27. Ahamed, S., Riaz, U., Kaushik, A., Alam, J.: Soft template synthesis of superparamagnetic ferrite nanoparticle: a novel technique. J. Inorg. Organomet. Polym. 19, 355-360 (2009)

28. Wang, S.X., Zhou, Y., Guan, W., Ding, B.J.: Preparation and characterization of stimuli responsive magnetic nanoparticles. Nanoscale Res. Lett. 3, 289-294 (2008)

29. Kady, A.S.A., Gaber, M., Hursei, M.M., Ebeid, E.Z.M.: Structural and fluorescence quenching of hematite nanoparticles. Spectrochim. Acta Part A 83, 398-405 (2011)

30. Sajeev, M.S., Moorthy, S.N., Kaliappan, R., Rani, U.S.: Gelatinisation characterization of cassava starch settled in the presence of different chemicals. Starch 55, 213-221 (2003)

31. Auoak, T., Deraz, N.M., Alarifi, A.S.: Synthesis of non-isothermal crystallization and magnetic properties of ferrite/poly(ethylene-co-vinylacetate) nanocomposites. Bull. Mater. Sci. 36, 417-427 (2013)

32. Sajeev, M.S., Kaliappan, R.: Effect of various process on settling of cassava starch. J. Roof Crops 34, 48-56 (2008)

33. Sung, J.H., Park, D.P., Bark, B.J., Choi, H.J., Jhon, M.S.: Phosphorylation of potato starch and its electro rheological suspension. Biomacromolecules 6, 2182-2188 (2005)

34. Fang, F.F., Liu, Y.D., Choi, H.J., Seo, Y.: Core-shell structured iron microspheres prepared via dual step functionality coatings and their magneto rheological response. ACS Appl. Mater. Interface 3, 3487-3495 (2011) 